\title{
Can soil respiration estimate neglect the contribution of abiotic exchange?
}

\author{
Xi CHEN ${ }^{1 *}$, WenFeng WANG ${ }^{1,2}$, GePing LUO ${ }^{1}$, Hui YE ${ }^{1}$ \\ ${ }^{1}$ State Key Laboratory of Desert and Oasis Ecology, Xinjiang Institute of Ecology and Geography, Chinese Academy of Sciences, \\ Urumqi 830011, China; \\ ${ }^{2}$ University of Chinese Academy of Sciences, Beijing 100049, China
}

\begin{abstract}
This study examines the hypothesis that soil respiration can always be interpreted purely in terms of biotic processes, neglecting the contribution of abiotic exchange to $\mathrm{CO}_{2}$ fluxes in alkaline soils of arid areas that characterize $5 \%$ of the Earth's total land surface. Analyses on flux data collected from previous studies suggested reconciling soil respiration as organic (root/microbial respiration) and inorganic (abiotic $\mathrm{CO}_{2}$ exchange) respiration, whose contributions in the total $\mathrm{CO}_{2}$ flux were determined by soil alkaline content. On the basis of utilizing meteorological and soil data collected from the Xinjiang and Central Asia Scientific Data Sharing Platform, an incorporated model indicated that inorganic respiration represents almost half of the total $\mathrm{CO}_{2}$ flux. Neglecting the abiotic module may result in overestimates of soil respiration in arid alkaline lands, which partly explains the long-sought "missing carbon sink".
\end{abstract}

Keywords: soil respiration; abiotic exchange; hypothetical system; incorporated model; missing carbon sink

Citation: Xi CHEN, WenFeng WANG, GePing LUO, Hui YE. 2014. Can soil respiration estimate neglect the contribution of abiotic exchange? Journal of Arid Land, 6(2): 129-135. doi: 10.1007/s40333-013-0244-1

Motivated by increasing atmospheric carbon dioxide and the climate changes it produced, the world's scientific community made a huge effort to investigate the sources and sinks in the global carbon cycle (Detwiler and Hall, 1988; Keeling et al., 1996). It was demonstrated that the global $\mathrm{CO}_{2}$ budget cannot be balanced unless a "missing carbon sink" is involved (Le Quéré et al., 2003). Numerous studies claimed to find the missing sink, but none of them were widely accepted (Tans et al., 1990; Schindler, 1999; Wofsy, 2001).

Alkaline soils are widely distributed over arid and semi-arid regions, occupying about $7 \times 10^{8} \mathrm{hm}^{2}$ or $10 \%-15 \%$ of arid and semi-arid soils (Xie et al., 2009). The arid and semi-arid soils represent $30 \%$ of the earth's land surface (Lal et al., 2003) and their area may further increase in this century under the current climatic conditions because of the global trend towards increasing desertification (Huenneke et al.,
2002). Over long time periods, large amounts of soil inorganic carbon (SIC) have been sequestered in the form of carbonates, which range from 750 to $950 \mathrm{Pg} \mathrm{C}$ (Schlesinger, 1985; Lal et al., 2000). It is the third largest global carbon pool, only less than the oceanic $(38,000 \mathrm{Pg} \mathrm{C})$ and soil organic (1,550 Pg C) carbon pools (Schlesinger, 1997). Considering the large SIC storage in alkaline soils of arid lands, these soils may be significant in the global carbon budget accounting.

Recent studies revealed that the role of SIC in the carbon cycle remains poorly understood, and the extent to which alkaline soils modulate the regional and global SIC dynamics is inadequately studied (Stevenson and Verburg, 2006). $\mathrm{CO}_{2}$ absorption by alkaline soils (disclosed by negative $\mathrm{CO}_{2}$ fluxes) was demonstrated in the Gurbantunggut Desert of China, suggesting alkaline soils could be a net $\mathrm{CO}_{2}$ sink (Xie et al., 2009). The sink size would be huge enough to explain the long-sought missing sink if it was represen-

*Corresponding author: Xi CHEN (E-mail: chenxi@ms.xjb.ac.cn) 
tative over other arid regions and in other ecosystems (Stone, 2008). The finding in the Gurbantunggut Desert is not anomalous. A study of the Railroad Valley (RRV) playa in Nevada, USA also revealed highly alkaline soil $(\mathrm{pH}>10)$ with an even higher rate of $\mathrm{CO}_{2}$ absorption (Yates et al., 2012). This role of abiotic $\mathrm{CO}_{2}$ fluxes in alkaline soils of arid lands in the global carbon cycle hence demands a better understanding.

The objective of this research was to examine whether the contribution of abiotic exchange to $\mathrm{CO}_{2}$ flux can be neglected when estimating soil respiration in arid alkaline soils. The concept of soil respiration was reconciled as organic and inorganic respiration. Using data collected from previous studies (Xie et al., 2009; Chen et al., 2013; Wang et al., 2013), the widely recognized $\mathrm{Q}_{10}$ model was incorporated with an abiotic module as suggested by a previous study (Wang et al., 2013) to quantify soil respiration and approximate the contribution of abiotic exchange. The role of arid alkaline soils in the global carbon cycle was estimated under the hypothesis that the parameters of the incorporated $\mathrm{Q}_{10}$ model are universally applicable.

\section{Materials and methods}

\subsection{Data sources}

The term "soil respiration" in the present study refers to "the apparent soil respiration" $\left(\mathrm{F}_{\mathrm{c}}\right.$, soil $\mathrm{CO}_{2}$ flux $)$. $F_{c}$ data were collected from previous studies conducted in three arid alkaline lands, the Tarim River Basin, Manas River Basin and Sangong River Basin of Xinjiang Uygur autonomous region of China (Xie et al., 2009; Chen et al., 2013; Wang et al., 2013). From 2005 to 2006, sterilization treatments on bare alkaline soils were launched in the Sangong and Tarim River Basins. Alkaline soils were sampled at bare sites from three ecosystems (alkaline-saline desert, abandoned farmland and oasis farmland) with 15 replications. Each soil sample was root-sieved, air-dried and divided into two subsamples, one of which was sterilized. Two LI-8100s were employed to simultaneously measure the $F_{c}$ of unsterilized and sterilized samples, as stated by Xie et al. (2009). In July of 2012, $F_{c}$ measurements with six replications were conducted at alkaline lands without vegetation in the Manas River Basin, covering three kinds of landforms (dry delta, alluvial plain and the edge of alluvial fan). The results further demonstrated $\mathrm{CO}_{2}$ absorption by alkaline soils, as described by Wang et al. (2013). The analyses presented in this study were based on surface air temperature $\left(\mathrm{T}_{\mathrm{as}}\right)$, soil alkalinity $(\mathrm{pH})$, soil temperature $\left(\mathrm{T}_{\mathrm{s}}\right)$ and water content $\left(\theta_{\mathrm{s}}\right)$ at a $0-5 \mathrm{~cm}$ depth. The data were collected from the Xinjiang and Central Asia Scientific Data Sharing Platform (http://midasia.geodata.cn/Portal/index.jsp).

\subsection{Modeling analysis}

Simultaneous measurements of $F_{c}$ of sterilized and unsterilized soil collars with sealed bottoms prove that soil sterilization is a feasible method for partitioning the biotic and abiotic flux components. However, this method requires laborious analyses, thus remains infeasible for large-scale application. It is almost impossible to gather data for intact alkaline soils in arid areas. Therefore, approximating $F_{c}$ partitions must be conducted using other methods. In a previous study, the $\mathrm{F}_{\mathrm{c}}$ model was developed from the $\mathrm{Q}_{10}$ model and formulated as (Wang et al., 2013):

$$
\left\{\begin{array}{c}
F_{\mathrm{c}}=F_{a}+F_{x} \\
F_{a}=R_{10} Q_{10}{ }^{(T-10) / 10} \\
F_{x}=r_{7} q_{7}{ }^{p H-7}+\lambda T+\mu \theta_{S}+e
\end{array} .\right.
$$

Where $\mathrm{r}_{7}$ is the referred value of $\mathrm{f}(\mathrm{pH})=\mathrm{r}_{7} \mathrm{q}_{7}{ }^{\mathrm{pH}-7}$ at $\mathrm{pH}=$ $7 ; \mathrm{q}_{7}$ is the factor by which $\mathrm{f}(\mathrm{pH})$ is multiplied when $\mathrm{pH}$ value increases by 1 ; and $\lambda, \mu$, and e are regression coefficients.

This presented an approximate method to quantify the contribution of soil abiotic $\mathrm{CO}_{2}$ exchange to $\mathrm{F}_{\mathrm{c}}$ in alkaline soils of arid areas. The determined parameter values are $\lambda=0.0059, \mu=0.0003, \mathrm{r}_{7}=3.0191, \mathrm{q}_{7}=0.7562$, $\mathrm{e}=-2.5081, \mathrm{R}_{10}=0.3625$, and $\mathrm{Q}_{10}=1.5$.

In this study, these parameters are hypothetically applicable worldwide, and so the model has global implications. The concept of soil respiration was reconciled as soil organic respiration (the root/microbial respiratory component) and soil inorganic respiration (soil abiotic $\mathrm{CO}_{2}$ exchange). It was also found to have a relationship with the temperature sensitivity of both components of the abiotic preponderance (defined as the proportion of negative $\mathrm{CO}_{2}$ flux). The traditional $\mathrm{Q}_{10}$ model was performed on flux data collected from previous studies to illustrate the necessity to incorporate an abiotic module when estimating alkaline soil respiration. With determined parameters, the above 
abiotic module $\left(\mathrm{F}_{\mathrm{x}}\right)$ was employed to approximate the soil inorganic respiration and evaluate the role of alkaline soils in the global carbon cycle.

\section{Results}

\section{1 $\mathrm{CO}_{2}$ flux system in alkaline lands}

A hypothetical system of alkaline soil $\mathrm{CO}_{2}$ fluxes was established. The system reconciles the concept of soil respiration as soil organic respiration (from biological processes) and soil inorganic respiration (from unknown non-biological processes), with a $\mathrm{CO}_{2}$ circulation hidden in the deep soil layers and even in the groundwater (Fig. 1). Note that the well-known abiotic processes, the formation and dissolution of soil carbonates and the subterranean ventilation of soil $\mathrm{CO}_{2}$ (Schimel et al., 1994) are not included in soil inorganic respiration. Such a partition is designed to encourage scientific explorations of soil inorganic respiration mechanisms after the exclusion of known abiotic processes.

Experimental analyses highlighted that soil $\mathrm{pH}$ level is a key factor in the $\mathrm{CO}_{2}$ flux system. A comparison between the responses to $T_{s}$ of $F_{c}$ in the steril- ized and unsterilized soils of alkaline-saline deserts (excluding sparse vegetation) indicated that the reduction of the sensitivity of $F_{c}$ to $T_{s}$ might be attributed to soil inorganic respiration in highly alkaline soils (Fig. 2).\#An exponential relationship between $F_{c}$ and $T_{a s}$ exists within each alkaline site (or each ecosystem) with a given degree of soil alkalization, but the robustness of the exponential relationships can differ among different sites (Fig. 3). According to the incorporated $\mathrm{Q}_{10}$ model, this finding might be explained by the difference in the degree of soil alkalization (soil $\mathrm{pH}$ ) between these alkaline sites. Coupled with the relationship between the soil $\mathrm{pH}$ and the proportion of negative $\mathrm{F}_{\mathrm{c}}$, soil $\mathrm{pH}$ is a key explanatory factor in the variability of $\mathrm{F}_{\mathrm{c}}$.

\subsection{Necessity to incorporate the abiotic module}

Performance of the traditional soil respiration model $\mathrm{F}_{\mathrm{c}}=\mathrm{R}_{10} \mathrm{Q}_{10}{ }^{\mathrm{Ts}-10 / 10}$ revealed that $\mathrm{F}_{\mathrm{c}}$ cannot be accurately described by the $\mathrm{Q}_{10}$ model with seasonal variability along two ecological gradients (soil alkalization and vegetation seasonality). This is more evident in the alkaline-saline desert than in the oasis farmland (Fig. 4). As alkaline-saline desert has a higher degree of

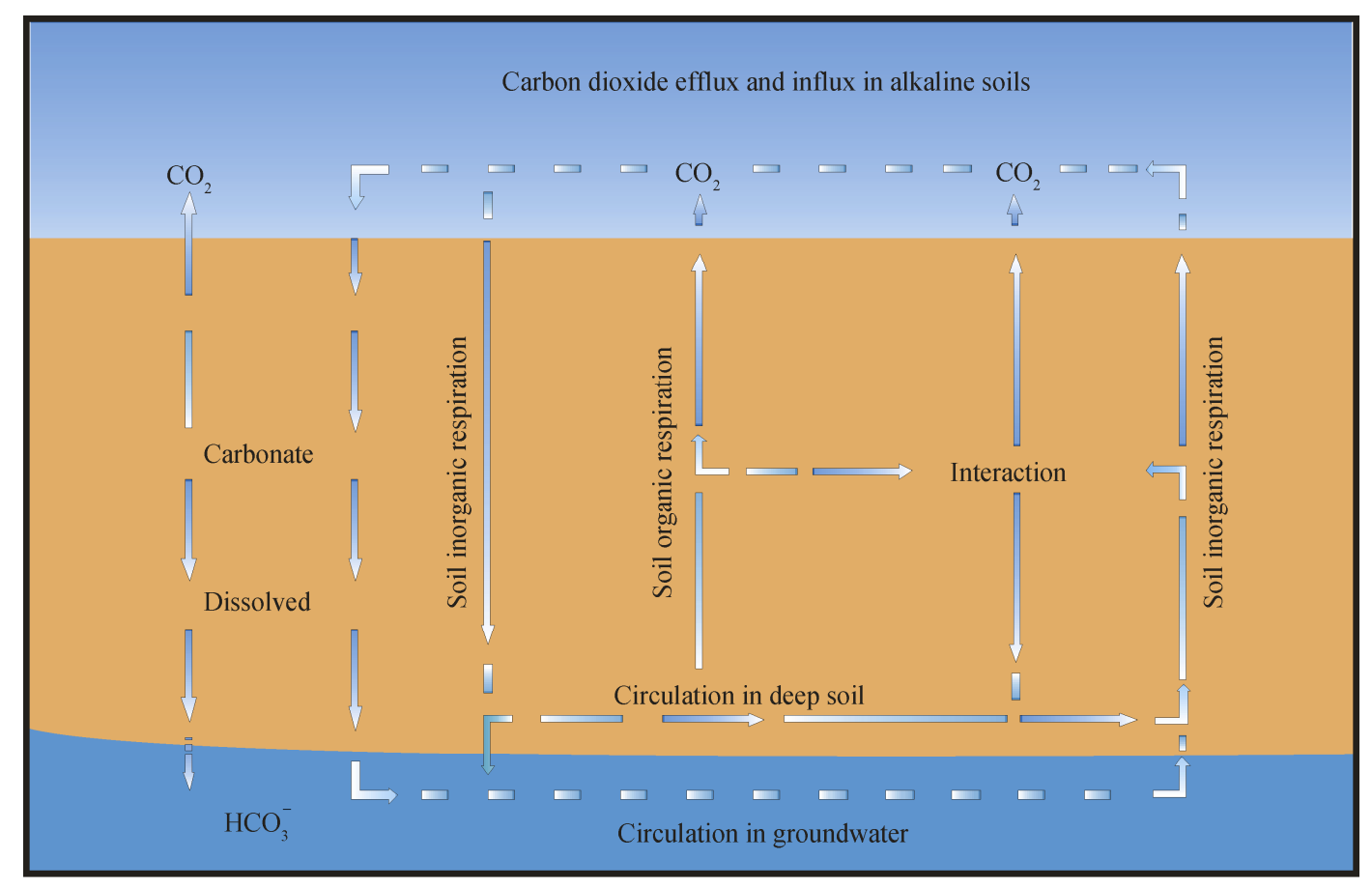

Fig. 1 A hypothetical system of carbon dioxide efflux and influx in alkaline soils, where the concept of soil respiration is reconciled as a sum of organic respiration (related to biological processes), inorganic respiration (from unknown non-biological processes) and interaction between them. The flux intensity is represented by the arrow length. 

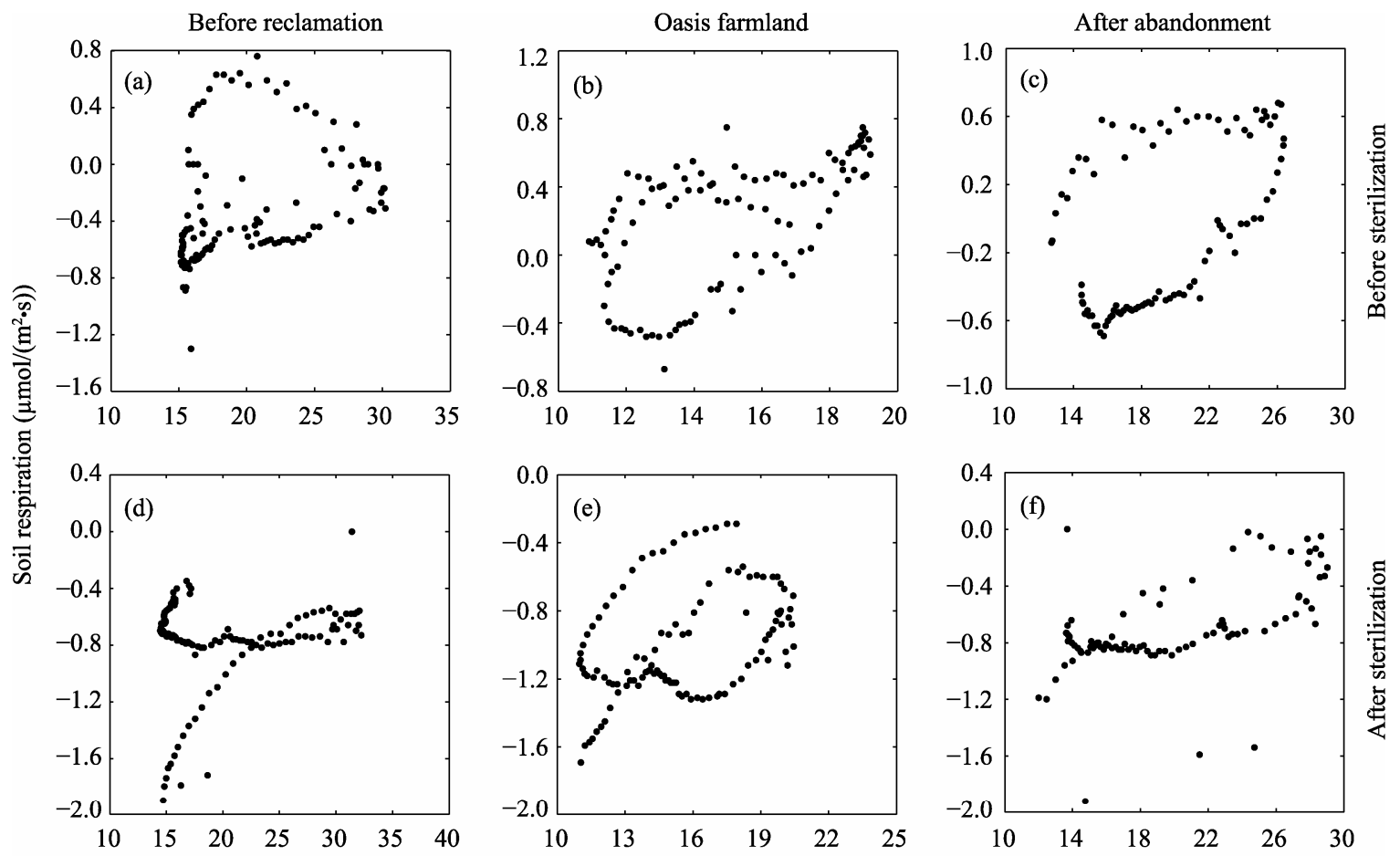

Soil temperature at the $0-5 \mathrm{~cm}$ soil depth $\left({ }^{\circ} \mathrm{C}\right)$

Fig. 2 Response of soil respiration $\left(F_{c}\right)$ to soil temperature at the $0-5 \mathrm{~cm}$ soil depth $\left(T_{s}\right)$ at three alkaline sites, where the $F_{c}$ was measured before $(a-c)$ and after $(d-f)$ soil sterilization (sparse vegetation was ruled out).
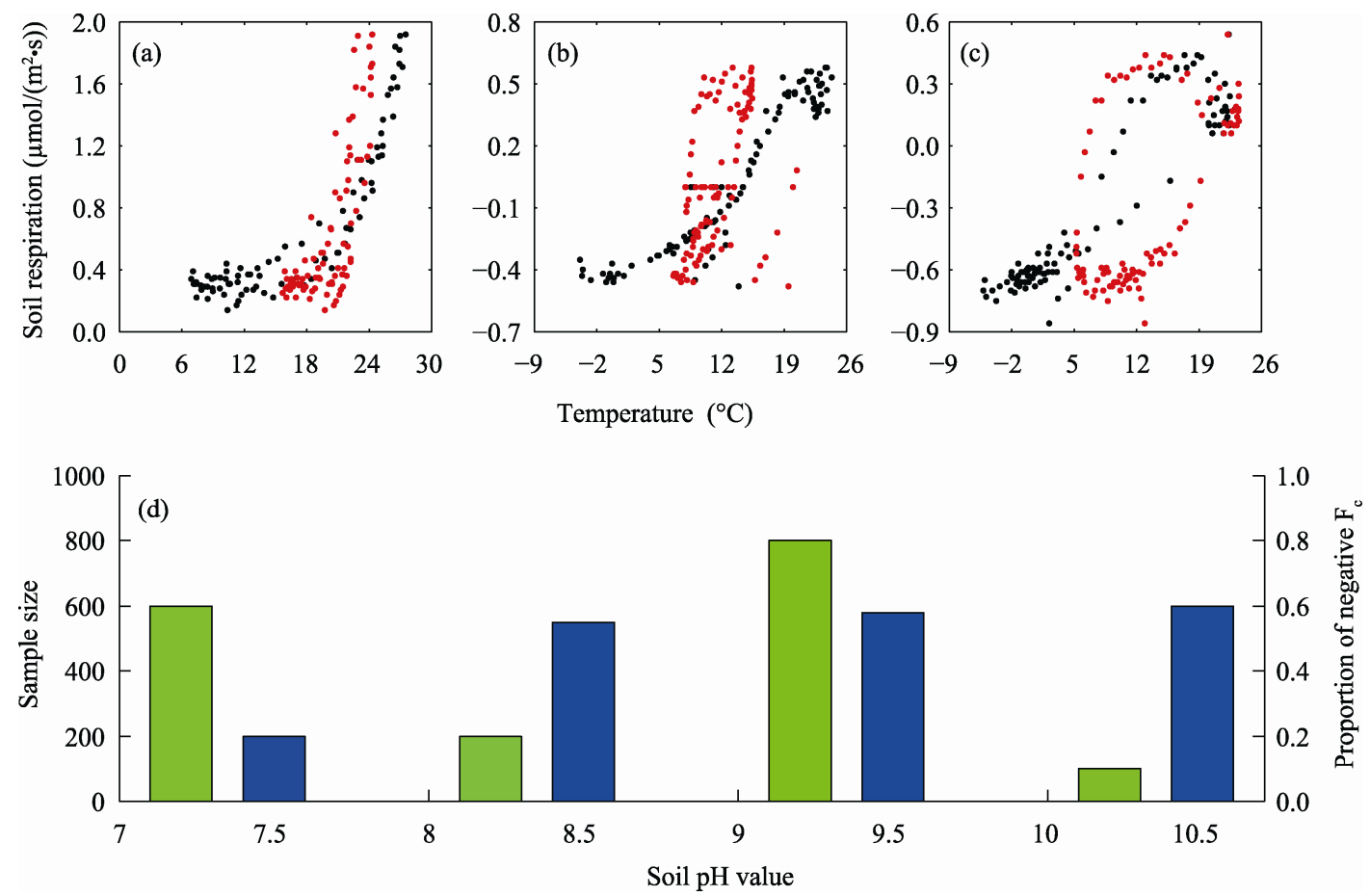

Fig. 3 Dependence of soil respiration $\left(\mathrm{F}_{\mathrm{c}}\right)$ on $\mathrm{T}_{\mathrm{s}}$ (red dots) and $\mathrm{T}_{\text {as }}$ (black dots) at sites with different $\mathrm{pH}$ values $(\mathrm{a}, \mathrm{pH}-8.5 ; \mathrm{b}, \mathrm{pH}-8.7 ; \mathrm{c}$, $\mathrm{pH}-9.2$ ) and the relationship between $\mathrm{pH}$ values and the proportion of negative $\mathrm{F}_{\mathrm{c}}(\mathrm{d})$. The proportion of negative $\mathrm{F}_{\mathrm{c}}$ (blue bars) and related sample size (green bars) are represented by the bar height. 

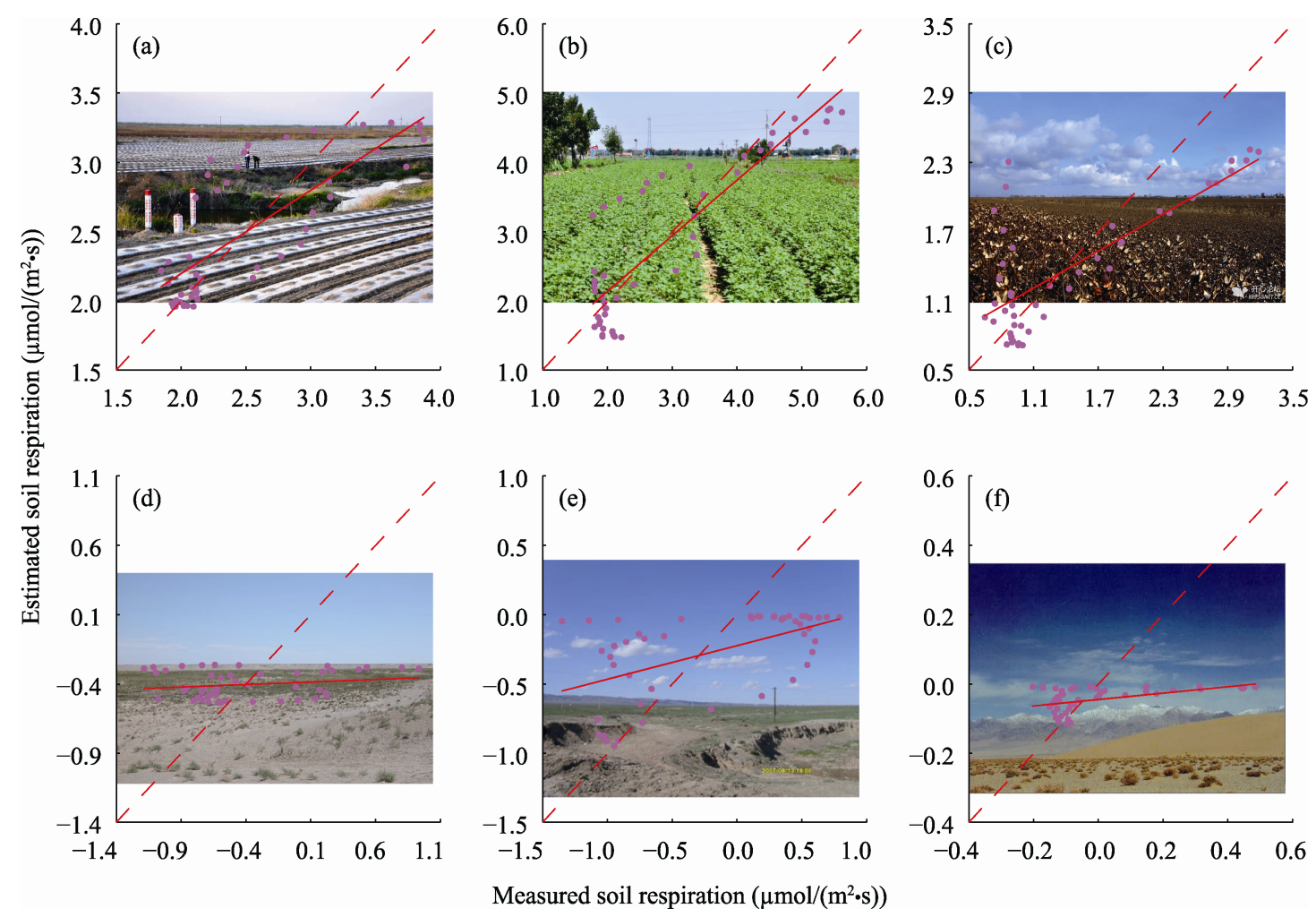

Fig. 4 Performance of the $Q_{10}$ model along double ecological gradients (soil alkalization and vegetation seasonality), where soil alkalization was compared between oasis farmland (a, spring; b, summer; c, autumn) and alkaline-saline desert ( $d$, spring; e, summer; f, autumn).

alkalization and salinization and less vegetation coverage, it therefore poses the question: do soil alkalinity and vegetation determine the dominance of soil organic and inorganic respiration that results in different sensitivities of $F_{c}$ to $T_{s}$ in the alkaline-saline desert and oasis farmland?

With the assumption that soil alkalinity and vegetation do have these effects, the hypothetical system of $\mathrm{CO}_{2}$ fluxes in alkaline soils was analyzed. Deficiencies in the $\mathrm{Q}_{10}$ model can be explained by the hypothetical system of $\mathrm{CO}_{2}$ fluxes in alkaline soils, as follows: soil organic respiration (with a well-known sensitivity to $\mathrm{T}_{\mathrm{s}}$ ) becomes weaker than soil inorganic respiration in the farmland during autumn, particularly at the end of the growing season, and cannot dominate $F_{c}$, so the deficiency in the $\mathrm{Q}_{10}$ model is more evident in autumn than in spring and summer. In alkaline-saline desert, however, perennial plants grow faster in summer, so the deficiency in the $\mathrm{Q}_{10}$ model is more evident in spring and autumn. The weaker abiotic processes never dominate $F_{c}$ and cannot explain such a difference.

\subsection{Analyses}

Using the incorporated $\mathrm{Q}_{10}$ model and meteorological and soil data (1979-2011) collected from the Xinjiang and Central Asia Scientific Data Sharing Platform implies that soil inorganic respiration represents almost half of the total soil respiration, suggesting arid alkaline soils might be the location of the long-sought "missing carbon sink". The overall soil organic respiration amounts to $0.68 \mathrm{Pg} \mathrm{C} / \mathrm{a}$, which is consistent with estimates of root/microbial respiratory components of soil respiration in the Biome-BGC model (0.7 $\mathrm{Pg} \mathrm{C} / \mathrm{a})$. The overall soil inorganic respiration amounts to $0.63 \mathrm{Pg} \mathrm{C} / \mathrm{a}$. The intensity of soil inorganic respiration is almost equal to that of soil organic respiration and the total sum of soil $\mathrm{CO}_{2}$ fluxes was only $0.05 \mathrm{Pg}$ $\mathrm{C} / \mathrm{a}$, implying that alkaline soils are only a slight source of the atmospheric $\mathrm{CO}_{2}$. Thus, arid soil respiration was likely overestimated by traditional $\mathrm{Q}_{10}$ models (Fig. 5). 


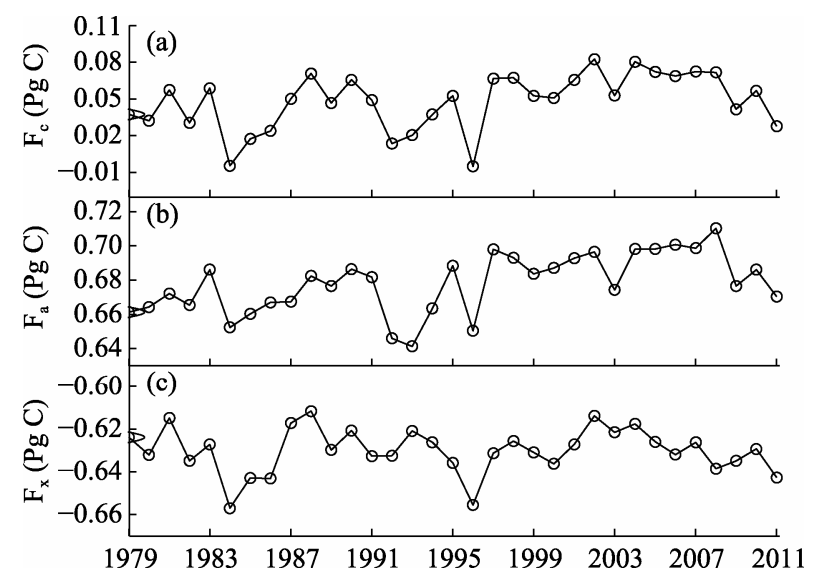

Fig. 5 Evolution of soil respiration $\left(F_{c}\right)$, soil organic respiration $\left(F_{a}\right)$ and soil inorganic respiration $\left(F_{x}\right)$ in Central Asia during 1979-2011 based on the incorporated modeling analysis

\section{Discussion}

Soil respiration was estimated by soil $\mathrm{CO}_{2}$ flux measurements (Schimel et al., 2001) and traditionally interpreted as roots/microbial respiration (Nguyen, 2003). Previously, a series of publications investigated the significance of soil $\mathrm{pH}$ on soil respiration, most of which focused on non-alkaline areas. Laskowshi (2003) investigated acidic forest soil (pH: 3.8-6.0) and found that soil $\mathrm{pH}$ was positively correlated with soil $\mathrm{CO}_{2}$ fluxes. This was also demonstrated in a subsequent investigation of acidic agricultural soil $(\mathrm{pH}$ : 3.4-6.8), which revealed that a significant, positive correlation existed between $\mathrm{pH}$ and soil basal respiration (Kermitt, 2006). All these studies suggested the inclusion of soil alkalinity as a main determinant in the empirical modeling of soil respiration. Differing from previous studies, this research focused on alkaline soils and found that soil $\mathrm{pH}$ was negatively correlated with soil $\mathrm{CO}_{2}$ fluxes.

The $\mathrm{Q}_{10}$ model has been utilized worldwide when quantifying the intensity of soil respiration, using temperature as the only global explanatory factor (Wang et al., 2010). However, results in both the present and previous studies suggest $\mathrm{pH}$ has a significant impact on soil respiration, especially on arid alkaline soils. The soil $\mathrm{pH}$ can thus be a significant factor to determine the intensity of soil respiration at both alkaline and non-alkaline sites. Reth et al. (2005) identified the influence of soil chemistry (including soil $\mathrm{pH}$ ) as an additional predictor and demonstrated the spatial variation of soil respiration in the studied field was significantly correlated with soil $\mathrm{pH}$. It is strongly suggested that soil $\mathrm{pH}$ be included in previous and future $\mathrm{Q}_{10}$ models for more reliable soil respiration experimental results, regardless of the alkalinity of the site.

This research implies that soil abiotic $\mathrm{CO}_{2}$ exchange is a crucial component of soil $\mathrm{CO}_{2}$ fluxes in alkaline soils in arid areas, and can explain the "anomalous" $\mathrm{CO}_{2}$ fluxes in the apparent soil respiration. Further research is still necessary to investigate whether these processes are significant in terrestrial $\mathrm{CO}_{2}$ sinks (Schlesinger et al., 2009). The introduction of the abiotic module in the incorporated model can be considered a descriptor for the part of $F_{c}$ that remains unexplained by the biotic module.

In alkaline dryland ecosystems (different from other carbonate ecosystems), the well-known abiotic processes include the abiotic subterranean ventilation of $\mathrm{CO}_{2}$ (Serrano-Ortiz et al., 2010; Sanchez-Cañete et al., 2011), dissolution of soil carbonates (Gombert, 2002; Kowalski et al., 2008), and groundwater recharge of dissoluble carbon (Scanlon et al., 2006). These processes were included in the hypothetical system (short arrows in the left side of Fig. 1). However, as stated in previous publications where flux data were collected (Chen et al., 2013; Wang et al., 2013; Xie et al., 2013), this research only considered clear days when these known abiotic processes are not hypothetically strong enough to affect the soil respiration's sensitivity to temperature. The interaction between soil organic and inorganic respiration only hypothetically existed, but further evidence is required. The inclusion of all these processes is complex, and the interaction between soil organic and inorganic respiration is also complicated. Therefore, further research on the system of alkaline soil $\mathrm{CO}_{2}$ fluxes and the incorporated soil respiration model is merited.

\section{Conclusion}

Soil respiration in alkaline soils of arid areas cannot be interpreted purely in terms of biotic processes since the contribution of abiotic exchange to $\mathrm{CO}_{2}$ flux is un-neglectable. The concept of alkaline soil respiration should be reconciled as soil organic respiration (the root/microbial respiratory component) and soil inorganic respiration (abiotic $\mathrm{CO}_{2}$ exchange). With 
parameters in the incorporated $\mathrm{Q}_{10}$ model hypothetically representing global convergent values, soil inorganic respiration represents almost half of the total soil respiration in alkaline lands. This suggests alkaline soils in arid lands are the location of the longsought "missing carbon sink".

\section{Acknowledgements}

This research was supported by the National Basic Research Program of China (2009CB825105). We are grateful to the Xinjiang and Central Asia Scientific Data Sharing Platform for access to data.

\section{References}

Chen X, Wang W F, Luo G P, et al. 2013. Time lag between carbon dioxide influx to and efflux from bare saline-alkali soil detected by the explicit partitioning and reconciling of soil $\mathrm{CO}_{2}$ flux. Stochastic Environmental Research and Risk Assessment, 27(3): 1-9.

Derwiler R P, Charles A S. 1988. Tropical forests and the global carbon budget. Science, 239: 42-47.

Gombert P. 2002. Role of karstic dissolution in global carbon cycle. Global and Planetary Change, 33: 177-184.

Huenneke L F, Anderson J P, Remmenga M, et al. 2002. Desertification alters patterns of aboveground net primary production in Chihuahuan ecosystems. Global Change Biology, 8: 247-264.

Keeling R F, Piper S C, Heimann M. 1996. Global and hemispheric $\mathrm{CO}_{2}$ sinks deduced from changes in atmospheric $\mathrm{O}_{2}$ concentration. Nature, 381: 218-221.

Kemmitt S J, Wright D, Goulding K W T, et al. 2006. pH regulation of carbon and nitrogen dynamics in two agricultural soils. Soil Biology \& Biochemistry, 38: 898-911.

Kowalski A S, Serrano-Ortiz P, Janssens I A, et al. 2008. Can flux tower research neglect geochemical $\mathrm{CO}_{2}$ exchange? Agricultural and Forest Meteorology, 148: 1045-1054.

Lal R, Kimble J M, Eswaran H, et al. 2000. Pedogenic carbonates and the global carbon cycle. In: Global Climate Change and Pedogenic Carbonates. Boca Raton, Florida: CRC Press, 1-14.

Lal R. 2003. Soil erosion and the global carbon budget. Environment International, 29: 437-450.

Laskowshi R, Maryański M, Niklińska M. 2003. Variance components of the respiration rate and chemical characteristics of soil organic layers in Niepolomice Forest, Poland. Biogeochemistry, 64: 149-163.

Le Quéré C, Aumont O, Bopp L, et al. 2003. Two decades of ocean $\mathrm{CO}_{2}$ sink and variability. Tellus B, 55: 649-656.

Nguyen C. 2003. Rhizodeposition of organic C by plants: mechanisms and controls. Agronomie, 23: 375-396.
Reth S, Reichstein M, Falge E. 2005. The effect of soil water content, soil temperature, soil $\mathrm{pH}$-value and the root mass on soil $\mathrm{CO}_{2}$ efflux-a modified model. Plant and Soil, 268: 21-33.

Sanchez-Cañete E P, Serrano-Ortiz P, Kowalski A S, et al. 2011. Subterranean $\mathrm{CO}_{2}$ ventilation and its role in the net ecosystem carbon balance of a karstic shrubland. Geophysical Research Letters, 38: L09802.

Scanlon B R, Keese K E, Flint A L, et al. 2006. Global synthesis of groundwater recharge in semi-arid and arid regions. Hydrological Processes, 20: 3335-3370.

Schimel D S, Braswell B H, Holland E A, et al. 1994. Climatic, edaphic, and biotic controls over storage and turnover of carbon in soils. Global Biogeochemical Cycles, 8: 279-293.

Schimel D S, House J I, Hibbard K A, et al. 2001. Recent patterns and mechanisms of carbon exchange by terrestrial ecosystems. Nature, 414: 169-172.

Schindler D W. 1999. The mysterious missing sink. Nature, 398: 105-107.

Schlesinger W H. 1985. The formation of caliche in soils of the Mojave Desert, California. Geochimica et Cosmochimica Acta, 49: 57-66.

Schlesinger W H. 1997. Biochemistry: An Analysis of Global Change $\left(2^{\text {nd }}\right.$ ed.). New York: Academic Press, 588.

Schlesinger W H, Belnap J, Marion G. 2009. On carbon sequestration in desert ecosystems. Global Change Biology, 15: 1488-1490.

Serrano-Ortiz P, Roland M, Sánchez-Moral S, et al. 2010. Hidden, abiotic $\mathrm{CO}_{2}$ flows and gaseous reservoirs in the terrestrial carbon cycle: review and perspectives. Agricultural and Forest Meteorology, 150: 321-329.

Stevenson B A, Verburg P S J. 2006. Effluxed $\mathrm{CO}_{2}-{ }^{13} \mathrm{C}$ from sterilized and unsterilized treatments of a calcareous soil. Soil Biology \& Biochemistry, 38: 1727-1733.

Stone R. 2008. Have desert researchers discovered a hidden loop in the carbon cycle? Science, 320: 1409-1410.

Tans P P, Fung I Y, Takahashi T. 1990. Observational constraints on the global atmospheric $\mathrm{CO}_{2}$ budget. Science, 247: 1431-1438.

Wang X H, Piao S L, Ciais P, et al. 2010. Are ecological gradients in seasonal $\mathrm{Q}_{10}$ of soil respiration explained by climate or by vegetation seasonality? Soil Biology \& Biochemistry, 42: 1728-1734.

Wang W F, Chen X, Luo G P, et al. 2013. Modeling the contribution of abiotic exchange to $\mathrm{CO}_{2}$ flux in alkaline soils of arid areas. Journal of Arid Land, doi: 10.1007/s40333-013-0187-6.

Wofsy S C. 2001. Where has all the carbon gone? Science, 292: 2261-2263.

Xie J X, Li Y, Zhai C X, et al. 2009. $\mathrm{CO}_{2}$ absorption by alkaline soils and its implication to the global carbon cycle. Environmental Geology, 56: 953-961.

Yates E L, Detweiler A M, Iraci L T, et al. 2012. Assessing the role of alkaline soils on the carbon cycle at a playa site. Environmental Earth Sciences, doi: 10.1007/s12665-012-2194-x. 